about 20 spherical masses, in which the egg-case is still intact, and also another damaged specimen which was found close to it. All the stages in the development of the contained embryos were traced, till they produced such young vorticellæ as are now shown among the empty egg-cases of the hydatina. The occurrence of infection is here again an impossible one. Germs of these ciliates are unknown, and no moving thing is ever seen within these intact egg-cases of hydatina till the little embryos become roused into active life, each within its own special cyst.

We have here, therefore, facts of an astounding nature, seeing that no sort of kinship $i_{\text {s }}$ known to exist between the comparatively complex rotifers and the unicellnlar organisms into which their eggs are transformed; and seeing, further, that totally different forms of ciliated infusoria are produced from the egg substance of the hydatina, according as it becomes transformed as a whole or only after having undergone segmentation into a varying number of small spherical masses.

These latter facts cannot but recall the varying products which, as I have shown, are also yielded by apparently similar masses of zooglœa; and such facts, together with the many other similar heterogenetic transformations which I have traced, and elsewhere described, compel me to believe that the forms of these lowest living things are as much the natural outcome of the polarities of their molecules-the "physiological units" of Spencer-as the varying forms of crystals are the necessary results of their intrinsic polarities under the conditions in which they are formed.

We know that these lower living things are most mutable and sensitive to changes in their medium, yet the accredited biological doctrines of the day ask us to believe, on the one hand, that all the forms of life that have ever lived have been derived from primordial forms which were first evolved untold ages ago upon the cooling surface of our planet; and, on the other hand, we are asked to believe that bacteria, monads, amœbæ, ciliated infusoria, and multitudes of other lowest forms of iife which are found to teem in all kinds of situations at the present day have resisted change and have been perpetuating their like during æons and æons of time. I must confess that this seems to me nothing less than an absurdity. Logic and the uniformity of natural phenomena would seem to negative the idea of an isolated and therefore miraculous origin of life. If archebiosis, or at all events processes of heterogenesis, such as I have been describing, ocour now and have been ever recurring we get an explana tion of the continued existence at the present day of the lowest forms of life all over the surface of the earth, the reason for which would otherwise be absolutely unintelligible from the point of view of the doctrine of evolution.

At this late hour $I$ can only hint at the importance of these views for medical science. Recognition of the de novo origin of bacteria does not tend to contradict any of the great body of bacteriological doctrine which has been built up during the last 30 years. It only tends to open the door rather wider and to put a reasonable check upon ultra-contagionist doctrines. There are indications, indeed, that the more philosophic bacteriologists are beginning to recognise the need of more moderation in this direction when we find Lehmann and Neumann, for instance, saying in their "Principles of Bacteriology," 3 "The division of bacteria into pathogenic and non-pathogenic, etc., as is still always done in text-books, has failed absolutely. We can understand and know the pathogenic varieties only if we study simul taneously the non-pathogenic, from which the former have once originated and still always originate" How much more, then, will it come to be recognised when the de novo origin of bacteria is generally admitted that we have to think of the origins of contagious diseases in the present day, instead of postulating the occurrence of such origins as possible only in a "remote geological past" about which we know nothing.

3 Translation of second edition, 1901, pp. 116-119.

Health of Ilfracombe.-Dr. E. J. Slade-King, medical officer of health of Ilfracombe, in his annual report for 1905 states that the death-rate was $11 \cdot 5$ per 1000 and this was the average from 1901 to 1904 . The birth-rate was $17 \cdot 3$ per 1000 . The infantile mortality was $84 \cdot 9$ per 1000 Dr. Slade-King describes the water-supply as constant and arple.

\section{A NEW MICROBE, PATHOGENIC FOR RODENTS, BACILLUS EQUI.}

\author{
By E. KLEIN, M.D., F.R.S.
}

Mr. Charles J. Humphrey, M.R.C.V.S., veterinary inspector, submitted to me a sample of blood of a horse that had suddenly died from an unknown cause. Mr. Humphrey had examined the blood of the animal with a possible view of detecting bacillus anthracis, but he failed to do so. Being anxious to have the diagnosis confirmed or negatived in order to have the required administrative regulations carried out he asked me to examine the above sample of blood. The animal-a private carriage horse-had been in the owner's possession for two and a half years and had not been laid up ill during that period. The horse was at work in the afternoon, returning to the stable at 5 P.M., and died at 7.45 P.M. the same evening.

The following were the chief symptoms at the post-mortem examination made by Mr. Humphrey. There was blood about both nostrils and the abdomen was swollen; the mesentery was inflamed in patches, with blood extravasations there were inflammatory patches along the large bowels the vessels were congested with extravasations, the mesen teric blood-vessels were engorged, and the lungs were congested. My best thanks are due to Mr. Humphrey for supplying me with the preceding notes. Film specimens of the blood showed a great many small and large groups of bacilli in these groups there were some not larger than a coccus, others long cylindrical, and all intermediary forms. From this it was therefore evident that Mr. Humphrey's preliminary diagnosis, "Not anthrax," was correct. I injected subcutaneously in the groin of a guinea-pig (1) with a fair dose of the blood-about 0.1 cubic centimetre. This guinea-pig developed a soft swelling in the groin and on the abdomen of the injected side but on the fourth day seemed quite lively. The animal was killed and on post-mortem examination showed about the seat of injection gelatinous infiltrations from which a large amount of turbid sanguineous fluid oozed out. Under the microscope the fluid, besides containing blood corpuscles, was crowded with short bacilli, some free, others in groups, some almost spherical, like cocci, others longer or shorter cylindrical; they were non-motile gram negative. Cultures : surface agar plate, agar tube, and gelatin tube proved that the fluid contained one species only of microbes, non-motile, gram negative, from 0.8 to several micromillimetres in length, in shape of all forms intermediate between coccus-like and cylindrical up to several $\mu$. It was therefore quite clear that this result negatived anthrax. All the viscera of the above guinea-pig appeared to be normal. With a single colony from the above agar plate injected subcutaneously in the groin one furthe $\mathrm{r}$ guinea pig (2). Next day this animal showed a soft slight swelling about the seat of injection. After another day the swelling had slightly increased, but the animal seemed quiet and off food. Four days after the injection it was in a dying condition. The post-mortem examination showed the following appearances: locally there was slight œdema and congestion; the spleen was enlarged and dark; on the parietal pericardium and the mediastinal pleura there were purulent pseudo-membranes; the lungs were much corgested. Films and specimens of the pseudo-membranes showed, bf sides the leucocytes constituting the pseudo-mem. brane, crowds of the bacilli, many intracellular, others free. In shape, size, and staining they were of the same characters as those user for the injection. Cultures made of a trace of the pseudo-membrane yielded pure cultures of the same species. Film specimens and cultures of the spleen showed great abundance of the same microbes. The heart's blood contained the microbe but not less in number, platinum loop of the blood yielding an almost confluent mass of colonies. With a single colony from an agar plate of the heart's blood of this guinea-pig injected subcutaneously one large rabbit. The animal died four days after; it had local inflammation, thin pseudo-membranes on the liver and an enlarged spleen, pseudo-membranes on the mediastinal pleura and the pseudomembranes of the liver, the spleen, and the pleura showed in film specimens and culture abundance of the bacilli; a similar result was obtained with tissue of the spleen; the heart's blood also contained great abundance of the bacilli.

Fro 2 these experiments it follows that the original blood 
of the horse contained abundance of a microbe which proved pathogenic and fatal to the guinea-pig and through this to the rabbit, the microbe in small doses (a single colony) causing death in four day $s$ with pseudo-membranes on the viscera, with abundance of the same microbe in the pseudomembranes, the heart's blood, and the spleen. The microbe, for which I propose the term "bacillus equi " resembles in shape and size the bacillus pseudo-tuberculosis (A. Pfeiffer), possessing all intermediate shapes between a coccus and a cylindrical, almost filamentous bacillus and being non-motile and not liquefying gelatin, but in action it obviously differs from it, the former causing acute illness and not producing the well-known necrotic nodules in the spleen, the liver, the lung, and the lymph glands characterising the action of the bacillus pseudo tuberculosis. The bacillus equi grows well at $37^{\circ} \mathrm{C}$. and at from $20^{\circ}$ to $21^{\circ} \mathrm{C}$. it forms round, more or less flat, moist, translucent colonies both on agar and on gelatin; it grows slower and is distinctly more translucent than bacillus pseudo-tuberculosis. The bacillus equi is practically gram negative; the oval forms, both of culture and of the animal tissues, show bipolar staining with methylene blue. The bacillus equi does not alter neutral red broth, litmus milk, lactosepeptone, or litmus glucose bile salts (MacConkey fluid). In alkaline beef broth it forms slight but uniform turbidity; no pellicle. Bacillus pseudo-tuberculosis leaves the fluid fairly clear but forms copiously granules and flocculi with pellicle on the surface (where the fluid touches the glass). The bacillus equi does not form spores and is devitalised by complete drying. Dr. Mervyn H. Gordon has kindly subjected in comparative series both the bacillus equi and the bacillus pseudo-tuberculosis to the various sugar tests and he finds as the chief and constant differences that while bacillus pseudo-tuberculosis forms acid from maltose and not from saccharose the bacillus equi bebaves in a contrary way, inasmuch as it forms acid from saccharose but not from maltose.

As already mentioned, the action of the bacillus pseudo tuberculosis and of the bacillus equi is fundamentally different. As a further distinction may be mentioned the fact that while bacillus pseudo-tuberculosis retains its pathogenic action unimpaired in subcultures after many months transference the bacillus equi rapidly loses its virulence in subcultures. The microbe of fowl cholera, with which the bacillus equi has certain morphological and cultural characters (including indol formation in broth) in common, differs from our microbe in (a) the bacillus of fowl cholera is virulent for mice and non-virulent for guinea-pigs, the bacillus equi is virulent for the guinea-pig and non-pathogenic for mice; and (b) the bacillus of fowl cholera curdles milk and reduces litmus and the bacillus equi does neither, milk remains fluid and litmus remains uncharged.

St. Bartholomew's Hospital.

\section{CRIER AND WIFE $v$. HOPE AND CURRIE:} (Specially reported for THE LANOET.)

IN the King's Bench Division on March 2nd, 5th, 6th, 7th, and 8 th, before Mr. Justice A. T. LA wrENCE and a special jury, Mr. William Fletcher Crier, an estate agent residing at Greenford, near Ealing, and his wife, Mrs. Mary Crier, sued Mr. George Hope and Dr. George Burnett Currie, partnere, practising in Ealing and neighbourhood, for damagec, alleging that by reason of the Jatter defendant's negligence Mrs. Crier had become infected with scarlet fever during ber confinement. Mr. GILL, K.O., and Mr. A. F ARLEIGH represented the plaintiffs; Mr. MCCALL, K.C., and Mr. NeILSON appeared for the defendants, who denied the charge of negligence.

In opening the case Mr. GILL stated that the plaintiffs were married early in 1903 and went to Greenford in 1904. The husband engaged Dr. Currie to attend his wife in her second confinement, which took place on Nov. 15th, 1904 . No complications took place until Nov. 18th, when the patient's temperature began to rise, eventually reaching $105^{\circ} \mathrm{F}$. On the following day a scarlet rash appeared on the body in addition to a sore-throat and on Nov. 20th Dr. Currie pronounced Mrs. Crier to be suffering from scarlet fever. Her condition for a time was very critical. Dr. Currie said that neither he nor his partner had any fever patients in their practice and therefore he could not account for the origin of the infection. This statement was untrue. Though there was no suggestion of lack of skill on Dr. Currie's part he (counsel) maintained that if a medical man attended an infectious case and then went to a confinement he did so at his own ri:k.

The first witness called was Miss SusAN BRown, a certificated nurse, who attended Mrs. Crier in 1903 for her first confinement and also in November, 1904. The witness stated that the latter confinement was normal save for a slight rupture of the perineum which required one stitch. The defendant, Dr. Currie, washed his hands in water, then corrosive sublimate, and lastly in lysol prior to examining the patient. He also removed his coat and was supplitd with an apron. He used a nail-brush. "White leg" was a complication. Mrs. Crier had suffered for some time previously from varicose veins. On Christmas Day Mrs. Crier's condition had so much improved that she was allowed up, but the next day she had a relapse which was followed by three rigors on Dec 30th, Jan. 6tb, and Jan. 11th. On Jan. 18th Dr. G. E. Herman was called in and opened a pelvic abscess, recovery following, though nurses were in attendance until April. The witness stated that she asked Dr. Currie in November as to the source of the infection and that he had replied, "I have not had a fever case for some time."

Mr. CRIER stated that on his arrival Dr. Currie removed his overcoat and muffler. After scarlet fever had been diagnosed Dr. Currie stated he "was not attending any fever cases " and was at a loss to account for it. Mrs. Crier's illness was notified on Nov. 21st and on the following day Mr. Hope, the medical officer of health, called and made inquiries of the witness. Dr. Currie's statement was repeated to his partner who expressed the opinion that he (Dr. Currie) could not have properly understood the query for he (Dr. Currie) was attending infectious cases. This interview was recounted to Dr. Currie who remarked, "He is a funny chap; you may take it from me that I have not had any." The witness stated that he had had inquiries made, with the result that he learnt that Dr. Currie had certified patients as suffering from scarlet fever on Oct. 15th and 17th, and Nov, 14th and 15th. When confronted with this evidence Dr. Currie is alleged to have observed, "What is a doctor to do?" The plaintiff stated that his claim for special damage amounted to $£ 500$, incurred by out-of-pocket expenses and loss of business, the latter being brought about by his constant and necessary attendance at home.

Cross-examined, he stated that he kept three servants, procured his goods from Harrod's Stores, and bis milk from a neighbouring farm. He went to business at Chiswick part]y by train and electric tram.

Mrs. MARY CRIER said that she was a nurse for five years prior to her marriage. Directly Dr. Carrie came into her room on Nov. 15th, some time about 7 or 8 P.M., he shook her hands prior to washing his own. He told her that he had no fever cases on her inquiring as to the source of her infection. After her first confinement in 1903 she had been in indifferent health.

Mrs. EllizabeTh Miller, a labourer's wife, stated that Dr. Currie visited her two children who were suffering from scarlet fever on Nov. 15 th, about 6 P.Mr.

Dr. Charles ErNest Goddard, medical officer of health of Wembley, and Mr. HERBERT EDWARD CounseiL, of Oxford, gave evidence and deemed it unwise for medical men to attend cases of confinement within so short a period as Dr. Currie had done after visiting a scarlet fever case, "even after taking proper precautions." It was a risk that members of the profession should not run except in the greatest emergency. The latter witness thought the septic trouble which culminated in the pelvic abscess to be due to the scarlet fever infection.

Mr. MCCALL, in outlining the defendants' case, remarked upon the amount of prejudice that had been introduced into the case. The only questions for the jury to consider were: (1) Did Dr. Currie convey infection to Mrs. Crier? and (2) Did he as a medical man in the circumstances exercise reasonable care?

In his evidence Dr. Currie stated that he visited the Millers' house on Nov. 15th but had no necessity to touch the boy, having diagnosed his condition on the previous day. Returning home he found a telegram summoning him to Greenford. Thereupon he washed and disinfected his hands and arms with lysol and changed his coat prior to driving the two and a half miles to Greenford. Before examining Mrs. Crier he had thoroughly disinfected himself as stated by Nurse Brown. He also used rubber sleeves to cover his shirt. 